\title{
Decisiones de Costos después de la Pandemia
}

\section{Por: Luis Landaverde}

Máster en Finanzas, Licenciado en Administración de Empresas, Docente-Investigador del Departamento de Contabilidad y Finanzas de la Universidad Centroamericana "José Simeón Cañas" (UCA).

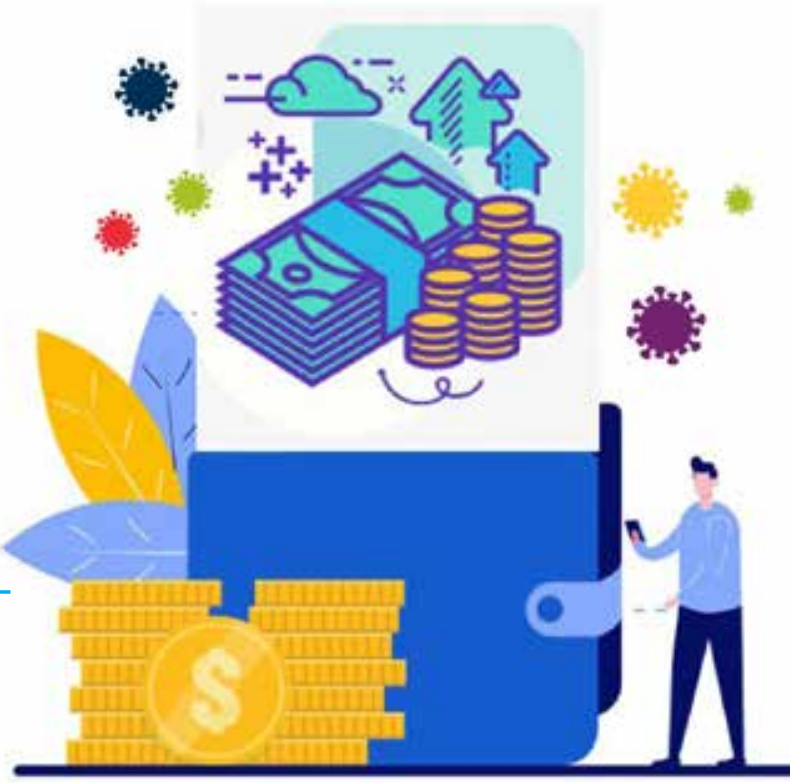

Después del escenario de una pandemia y sus efectos económicos y financieros cada empresa en particular se vuelve precursor del mejoramiento y reactivación de la economía salvadoreña, contexto en el cual la revisión y actualización de su estructura de costos son claves para enfrentar las consecuencias de la crisis.

En el presente artículo de opinión se muestran y explican algunos lineamientos a tomar en cuenta para el desarrollo de una eficiente gestión de costos en virtud de los planes y operaciones que se llevarán a cabo en los periodos futuros; donde las empresas y quienes toman las decisiones esperan los mejores resultados posibles en materia financiera.

Palabras Clave: Costos, gerencia, decisiones, evaluar, gestión, rentabilidad, estrategia.

Cuando se elaboran proyecciones financieras de un negocio, ya sea dentro de un marco operacional o de futuros emprendimientos, siempre se desea que los resultados sean satisfactorios y que cumplan los objetivos financieros deseados. Uno de los objetivos financieros a los que se les brinda mayor atención es la generación de rentabilidad de la compañía, pues estamos acostumbrados a aceptar y realizar inversiones tomando en cuenta los indicadores de rentabilidad obtenidos.

El concepto de rentabilidad es definido como una relación de ingresos y costos generados por el uso de recursos en actividades productivas de una compañía (Gitman y Ulate, 2008). Por ende, cuando los objetivos van encaminados a la generación máxima de utilidades también tenemos que preocuparnos por evaluar y analizar la gestión de la estructura de costos que tengamos en ese momento porque la generación de utilidades, aparte de depender de la capacidad de generación de ingresos, dependerá del grado de importancia y aplicación de una eficiente gestión de los costos de la compañía.

Lamentablemente, debemos reconocer que, en algunos casos, la gestión de los costos y su contabilidad se vuelve un área muy complicada para algunos administradores, gerentes y tomadores de decisiones, a tal punto de subestimarla en las decisiones financieras o limitarla a un simple registro contable obligatorio. Sin embargo, esa es una percepción incorrecta ya que hablar de costos también es hablar de contabilidad administrativa, entendida desde un rol como sistema de información interno al servicio de las necesidades de la administración y orientada a las funciones de planeación, control y toma de decisiones (Ramírez Padilla, 2013). En ese sentido, la información resultante del análisis de los costos de una compañía siempre tiene su mayor fundamento en su capacidad de responder al trabajo administrativo y decisiones internas y gerenciales de la compañía y ese debe ser su enfoque.

Después de este suceso global ocurrido en el presente año, en donde una pandemia originada por el COVID-19 nos enseñó que hasta un buen plan empresarial puede fallar, nos queda claro que la correcta gestión de costos es más que necesaria ya que la información que obtengamos de un buen análisis de nuestros costos nos ayudará en la creación de estrategias más realistas para la compañía. Para los períodos futuros es de vital importancia que la gestión de costos siempre vaya encaminada a una administración estratégica, tanto en el corto como en el largo plazo; $y$, debemos cerciorarnos que sea así ya que lo acontecido a nivel mundial con esta pandemia nos deja la experiencia que el largo plazo solo puede ser viable según las decisiones preventivas que se tomen en el corto plazo. 


\section{LA NECESIDAD DE EVALUAR}

Después de varios meses de cuarentena obligatoria y cierre total de las actividades económicas y comerciales, el país inició a mediados del 2020 un proceso de reactivación económica. En ese contexto, un primer consejo que aplicar en las empresas es la necesidad de revisión, de los sistemas de información de costos actuales, es decir, evaluar para asegurarse que la información que se brinda sobre sus costos actuales sea la idónea y que contribuya, estratégicamente, al logro de objetivos de rentabilidad futuros.

Este consejo se trae a la discusión debido a que la mayoría de empresas salvadoreñas carecen de orden en sus finanzas generales $y$, por tanto, no se aplica una adecuada medición de sus costos operacionales. Esto, probablemente, tiene su origen en la falta de conocimiento sobre la aplicación de los métodos de costeo o, simplemente, por una decisión propia de funcionar según la lógica y experiencia que los liderazgos de la empresa consideran correcta.

Asimismo, las empresas deben realizar la evaluación y revisión constante de su información de costos puesto que los sistemas de información empresariales son dinámicos, lo que significa que también se deben ajustar y adecuar a las necesidades que van surgiendo, más hoy en día, cuando los procesos de la empresa seguramente tendrán cambios significativos para lograr adecuarse a la nueva dinámica del mercado.

\section{FAVORECER COSTOS EFECTIVOS}

Para conseguir beneficios debe de invertirse una cantidad necesaria de recursos, y con esta inversión obtener las utilidades que se desean (Rodríguez, 2012). En esta relación entre recursos utilizados y beneficios obtenidos debe de crearse un proceso de análisis con el fin de medir la capacidad real que posee una compañía para generar rentabilidad ya que es importante evaluar como el uso de nuestros recursos, que generan costos, contribuyen a este logro financiero. Y más de alguna vez hemos escuchado los términos de eficiencia y eficacia aplicados a nuestra actividad empresarial, sin embargo, desde la perspectiva de los costos, debemos buscar la efectividad en la gestión de costos y su efecto desde el punto de vista de la rentabilidad.

Favorecer costos efectivos es mucho más importante que ser eficientes y eficaces porque, generalmente, las personas tomadoras de decisiones se enfocan en aquellas erogaciones que contribuyen a alcanzar los objetivos sin considerar los aprovechamientos o derroches que surgen para el logro de esas metas, una muestra inequívoca de un enfoque basado en resultados. Asimismo, cuando se reflexiona y se establecen procesos para disminuir el desaprovechamiento de estos recursos se logra ser más eficiente en su uso, pero normalmente está limitado a una acción en el corto plazo plasmada, generalmente, en un presupuesto. Lo que refleja que estará condicionada por un objetivo a corto plazo en materia de uso adecuado de recursos.

En cambio, cuando la importancia recae en generar costos efectivos estamos tomando en cuenta los beneficios en rentabilidad y en la optimización en el uso de los recursos a un largo plazo lo que permite que esto sea parte de la información necesaria para una planeación estratégica. Los costos establecidos por parte de las empresas deben de ser totalmente efectivos y deben de construirse representando el uso óptimo de los recursos que permitan generar los retornos de rendimiento adecuados para las compañías.

Por tanto, la definición de costos efectivos se vuelve parte indispensable de indicadores de retornos de rentabilidad que nos permite contrastar el uso adecuado de los costos y su aporte en los análisis de rentabilidad de la compañía para así determinar su verdadera contribución a los objetivos de un plan estratégico. De la misma manera, debemos tomar en cuenta que concentrarse en resultados eficaces sin ser efectivos puede causar problemas en otras áreas financieras a largo plazo como, por ejemplo, en el deterioro de la liquidez, aumento de endeudamiento, así como dificultades en la gestión operativa de calidad y en la mejora de procesos internos a futuro.
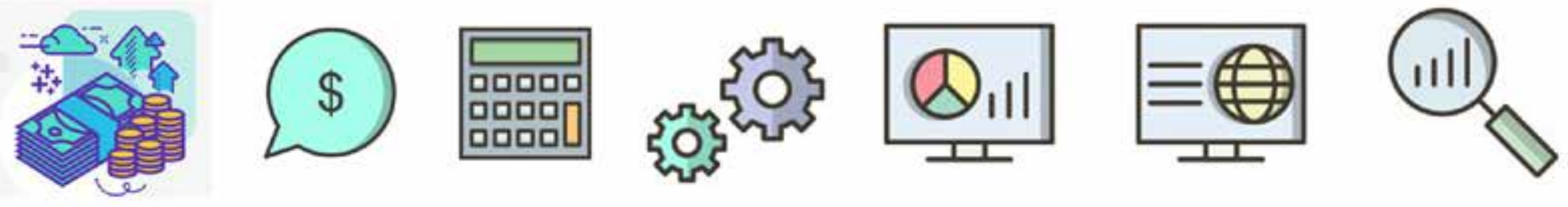


\section{RECONOCER EL IMPACTO DE LOS COSTOS FIJOS}

Los costos fijos de una entidad son aquellos que permanecen constantes dentro de un rango de tiempo relevante de producción (Polimeni, Fabozzi, Adelberg, 1994) e, independientemente cual sea el método de cálculo de costos implementado por una compañía, es de vital importancia reconocer que una estructura de costos siempre tendrá un componente de erogación fijo que será autónomo de las decisiones que se tomen en materia de volumen de actividad, ya sea producción o ventas.

Cuando analizamos la estructura fija de los costos nos involucramos con información interna de la empresa con la cual es difícil tomar una decisión para tener control gerencial total. En estos costos fijos no podemos incidir a través del control de un volumen de unidades fabricadas ni vendidas, por ejemplo, porque prácticamente no depende del nivel de actividad de la empresa, sino más bien, de su capacidad de producción ya instalada a la cual hay que sostener. Esto implica una mayor dificultad para adaptarse a nuevos escenarios financieros. Por tanto, en este proceso de reactivación económica es indispensable que las empresas conozcan la cuantía de sus costos fijos actuales, que la compare con su nivel de producción y la proporción que representan de un coste total; así podrá determinar su nivel de apalancamiento operativo, es decir, conocer el nivel de impacto actual de los costos fijos en su estructura total de costos y, por ende, podrá conocer y considerar el impacto de los costos fijos en su rentabilidad.

Una compañía con menos estructura fija y más estructura variable tiene mayor control de decisión sobre la cuantía de sus costos y, por tanto, los efectos negativos de la suspensión de operaciones son menos drásticos y más controlables, de hecho, la insostenibilidad de operaciones que la mayoría de empresas sufrieron a raíz de esta reciente pandemia se debe a la falta de pagos de la estructura fija de sus costos, y no tanto un problema de costos variables, pues pago de sueldos fijos, alquileres, pago de servicios fijos, pago de cuotas de préstamos son erogaciones que se generan periódicamente, independientemente existan o no ingresos generados por ventas. Al final, los costos fijos son los determinantes para decidir si una empresa es rentable o no, y a medida pasa el tiempo es importante tomar acciones a corto y largo plazo sobre el tratamiento que se le brindará a los costos fijos actuales con el fin de poderlos convertir a costos variables o tomar decisiones en términos de indicadores de generación de ingresos y rentabilidad que permitan amortiguar los efectos de un fuerte apalancamiento operativo de las compañías.

Bibliografia:

Gitman, L. J. y Ulate, R. (2008). Principios de Administración Financiera. 12 ed., Pearson. Polimeni, R. S., Fabozzi, F. J. y Adelberg, A. (1994). Contabilidad de Costos. McGraw Hill. Ramírez Padilla, D. N. (2013). Contabilidad Administrativa. Mc Graw Hill.

Rodríguez Morales, L. (2012). Análisis de Estados Financieros. Mc Graw Hill.
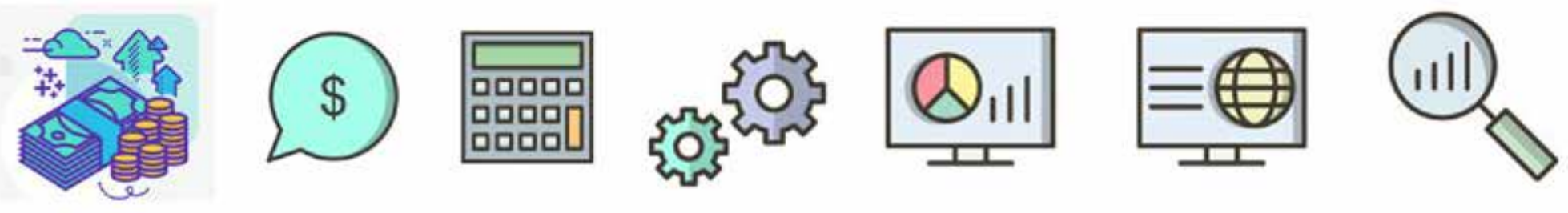